\title{
Silver(I) coordination polymers with thioether ligands: the influence of fluoro-substitution
}

Hangxing Xiong, ${ }^{\mathrm{a}} \mathrm{Li} \mathrm{Li},{ }^{\mathrm{a}}$ E Liu, ${ }^{\mathrm{a}}$ Chengxiong Yang, ${ }^{\mathrm{a}}$ Yuan Zhuo Zhang, ${ }^{\mathrm{b}}$ James C. Fettinger ${ }^{\mathrm{c}}$ and Guoqi Zhang ${ }^{\mathrm{b}} *$

${ }^{a}$ College of Chemical Engineering and Pharmacy, Jingchu University of Technology, Jingmen 448000, China

${ }^{b}$ Department of Sciences, John Jay College and The Graduate Center, The City University of New York, New York, NY 10019, USA

${ }^{c}$ Department of Chemistry, University of California Davis, Davis, CA 95616, USA

*Corresponding author. Email address: guzhang@jjay.cuny.edu

Keywords: Thioether; Silver(I); Fluorine; Crystal structure; Coordination polymer

\section{ABSTRACT}

A fluoro-substituted thioether ligand, 1,4-bis(phenylthiomethyl)-2,3,5,6-tetrafluorobenzene $\left(\mathrm{L}^{\mathrm{F}}\right)$ was synthesized to compare the solid-state structures and silver(I) coordination chemistry with ligand L without fluoro-substitutions. The crystal structures of both ligands have been determined by X-ray diffraction technique and the results revealed that fluorosubstitution has an important impact on the molecular conformations and crystal packing patterns. The solution reactions of two ligands $\left(\mathrm{L}\right.$ and $\mathrm{L}^{\mathrm{F}}$ ) with silver(I) hexafluorophosphate afforded their $\mathrm{Ag}(\mathrm{I})$ complexes $\mathbf{1}$ and $\mathbf{2}$, respectively, with good-quality crystals which have been structurally characterized by X-ray diffraction analysis. While 1 including ligand L displays a 3-dimensional (3-D) coordination network, where silver(I) adopts pseudotetradedral coordination geometry, 2 shows a 1-D polymeric chain with di-coordinate silver(I) ions being bridging metal nodes. The remarkable difference observed in silver(I) coordination chemistry further highlights the role of fluoro-substitution in governing the metal-driven self-assembly process involving thioether compounds. The thermal properties of both ligands and silver(I) complexes have been investigated. 


\section{Introduction}

Supramolecular chemistry involving metal-ligand interactions (coordination bonding) has been continuingly expanding as an important branch of chemical science in recent years [1]. Infinite metal-ligand assemblies, i.e. coordination polymers or networks have found widespread applications in materials studies such as gas sorption/storage, molecular sensing/separation, heterogeneous catalysis, optical and magnetic materials [2]. It is, therefore, of current interest to prepare and characterize novel coordination polymers with intriguing physical and/or chemical properties. To approach this, the central event one would consider is the choice of suitable organic ligands. To date, a plethora of research efforts have been focused on the utilization of $\mathrm{N}$ - and/or O-rich ligands [3], yet the softer S-donor ligands were relatively little addressed, probably due to the fact that they have poor thermostability and are opt to air oxidation $[4,5]$. Silver(I) is an ideal metal connecting unit that shows potential in constructing diverse supramolecular compounds and coordination polymers, because of its high coordination flexibility. Since silver(I) shows good affinity to S-ligands (thioether ligands), the Ag-S coordination chemistry has been explored for a long time [6]. Of interest are the supramolecular assemblies based on thioether ligands containing discrete multiple S-donating sites [7]. We have previously studied the role of anions in driving the formation of diverse 1-3D network structures of four silver(I) coordination polymers built on a structurally related thiother ligand, 1,3bis(methylthiomethyl)benzene [8].

Fluorine is a particularly important element in organic chemistry owing to the extraordinary potential of fluorine-containing organic molecules in modern biomedical applications. Indeed, the introduction of fluorine atoms into biologically active molecules towards improved drug performance has become a common practice in current drug discovery [9]. Besides, the fluorine substitution on organic molecules was also known to remarkably influence the properties of certain materials, especially conjugated polymers [10]. Except for the changes on the electronic properties and bond polarity of molecules caused by fluorine substitution, the existence of fluorine atoms often results in a variety of supramolecular interactions $(\mathrm{F} \ldots \mathrm{H}, \mathrm{F} \ldots$ halogen and 
F... $\pi$ interactions) upon molecular packing due to its high electronegativity [11]. To better understand the role of fluorine atoms play in altering the biological and materials properties, it is critical to investigate the structural chemistry of organic and metal-organic compounds involving the fluoro-substitution effect at the molecular level.

In this work, we describe the silver(I) coordination chemistry of a symmetrical thioether ligand, 1,4-bis(phenylthiomethyl)benzene (L) and its tetrafluoro-substituted derative, 1,4-bis(phenylthiomethyl)-2,3,5,6-tetrafluorobenzene $\left(\mathrm{L}^{\mathrm{F}}\right)$ (Scheme 1), with a focus on the comparison of the solid-state structures for both ligand molecules and silver(I) coordination complexes. The crucial impact of fluorine on both the molecular conformations of ligands and the coordination modes of the corresponding silver(I) complexes is discussed.

Scheme 1. The molecular structures of ligands $L$ and $\mathrm{L}^{\mathrm{F}}$.

\section{Experimental}

\subsection{General}

Solvents and reagents were purchased from Fisher Scientific or Sigma-Aldrich in the US. All reactions were performed under ambient conditions (no inert atmosphere). FT-IR spectra were measured on a Shimadzu 8400S instrument with solid samples using a Golden Gate ATR accessory. Thermogravimetric analysis (TGA) was carried out on a Shimadzu TG-50 
analyzer under $\mathrm{N}_{2}$ atmosphere with a heating rate of $20{ }^{\circ} \mathrm{C} / \mathrm{min} .{ }^{1} \mathrm{H},{ }^{13} \mathrm{C}$ and ${ }^{19} \mathrm{~F} \mathrm{NMR}$ spectra were obtained at room temperature on a Bruker III $500 \mathrm{MHz}$ spectrometer with TMS as an internal standard. High resolution mass spectra were recorded on an Agilent 6550 iFunnel ESI-QTOF-LC/MS instrument. Elemental Analyses were performed by Midwest Microlab LLC in Indianapolis. Ligand L was prepared according to the literature procedure [12].

\subsection{Synthesis of 1,4-bis(phenylthiomethyl)-2,3,5,6-tetrafluorobenzene $\left(L^{F}\right)$}

The procedure is similar to that for $\mathrm{L}$. Thiophenol $(2.2 \mathrm{~mL}, 21.5 \mathrm{mmol})$ was added to a solution of potassium ahydroxide $(1.2 \mathrm{~g}, 30 \mathrm{mmol})$ in $15 \mathrm{ml}$ ethanol at $0{ }^{\circ} \mathrm{C}$ and the reaction mixture was stirred for $1 \mathrm{~h}$ at this temperature. Bis(bromomethyl)tetrafluorobenzene $(2.64 \mathrm{~g}$, $10 \mathrm{mmol}$ ) was then added to the reaction [13]. The resulting mixture was slowly warmed to room temperature and allowed to stir for additional $16 \mathrm{~h}$, after which time the reaction was quenched with water and extracted with dichloromethane. The organic layer was then washed with $2 \mathrm{~N}$ aqueous sodium hydroxide solution and brine, dried over anhydrous $\mathrm{Na}_{2} \mathrm{SO}_{4}$. The filtrate was evaporated under reduced pressure to give pale yellow crude product which was purified by recrystallization from hexane/ethyl acetate to give $\mathrm{L}^{\mathrm{F}}$ as a white solid in $63 \%$ yield (2.5 g). ${ }^{1} \mathrm{H}$ NMR (500 MHz, $\left.\mathrm{CDCl}_{3}\right) \delta$ 7.40-7.38 (m, 4H), 7.32-7.29 (m, 6H), 4.11 (s, 4H) ppm; ${ }^{13} \mathrm{C}$ NMR $\left(125 \mathrm{MHz}, \mathrm{CDCl}_{3}\right) \delta$ 145.5-145.2 (m), 143.5-143.3 (m), 133.8, 132.5, 129.1, 128.0, 116.4-116.2 (m) ppm; ${ }^{19} \mathrm{~F}$ NMR (377 MHz, $\left.\mathrm{CDCl}_{3}\right) \delta-143.6$ (s, 4F) ppm. HRMS (ESI): calc'd for $\mathrm{C}_{20} \mathrm{H}_{14} \mathrm{~F}_{4} \mathrm{~S}_{2}[\mathrm{M}]^{+}$394.0473, found 394.0480.

\subsection{Synthesis of compound $\left\{\mathrm{Ag}(L)_{2} \cdot P F 6\right\}_{n}(\mathbf{1})$}

Ligand L (32.2 mg, $0.100 \mathrm{mmol})$ was dissolved in $\mathrm{CH}_{2} \mathrm{Cl}_{2}-\mathrm{MeOH}(10 \mathrm{~mL}, 1: 1$, v/v) in a 20 $\mathrm{mL}$ vial, to which an acetonitrile solution of $\mathrm{AgPF}_{6}(50.4 \mathrm{mg}, 0.200 \mathrm{mmol})$ was added upon stirring at room temperature. The resulting solution was allowed to stir for $10 \mathrm{~min}$ and then filtered. Slow evaporation of the filtrate over a week afforded colourless crystals of 1 that are suitable for X-ray diffraction analysis. The product was collected by decanting the solvent and then washed with diethyl ether, and dried in the air. Yield: $32.5 \mathrm{mg}$ (73\% based on L). FT-IR (solid, $\mathrm{cm}^{-1}$ ): 1578m, 1480w, 1439m, 1238w, 1203w, 1022w, 879m, 834s, 743s, 689s, 556s. Anal. Calcd. for $\mathrm{C}_{40} \mathrm{H}_{36} \mathrm{AgF}_{6} \mathrm{PS}_{4}$ : C 53.51, H 4.04\%. Found C 53.42, H 4.09\%. 


\subsection{Synthesis of compound $\left\{A g\left(L^{F}\right) \cdot P F_{6}\right\}_{n}(2)$}

Ligand $\mathrm{L}^{\mathrm{F}}(24.5 \mathrm{mg}, 0.062 \mathrm{mmol})$ was dissolved in $\mathrm{CH}_{2} \mathrm{Cl}_{2}-\mathrm{MeOH}(10 \mathrm{~mL}, 1: 1, \mathrm{v} / \mathrm{v})$ in a 20 $\mathrm{mL}$ vial, to which an acetonitrile solution of $\mathrm{AgPF}_{6}(30.2 \mathrm{mg}, 0.120 \mathrm{mmol})$ was added upon stirring at room temperature. The resulting solution was allowed to stir for $10 \mathrm{~min}$ and then filtered. Slow evaporation of the filtrate over 10 days afforded colourless crystals of $\mathbf{2}$ that are suitable for X-ray diffraction analysis. The product was collected by decanting the solvent and then washed with diethyl ether, and dried in the air. Yield: $27.0 \mathrm{mg}$ (67\% based on L). FT-IR (solid, $\mathrm{cm}^{-1}$ ): 1493s, 1443w, 1301s, 1182w, 1131w, 991s, 827s, 744s, 685s, 621m, 556s. Anal. Calcd. for $\mathrm{C}_{20} \mathrm{H}_{14} \mathrm{AgF}_{10} \mathrm{PS}_{2}$ : C 37.11, H 2.18\%. Found C 37.22, H 2.10\%.

\subsection{X-ray Structural Determinations}

Suitable crystals of the compounds were mounted on Cryoloops with Paratone-N oil. Data were collected with a Bruker APEX II CCD using Mo-Ka radiation and corrected for absorption with SADABS and structures solved by direct methods. All non-hydrogen atoms were refined anisotropically by full-matrix least squares on $\mathrm{F}^{2}$. Hydrogen atoms were found from Fourier difference maps and refined isotropically, otherwise they were placed in calculated positions with appropriate riding parameters. Crystal structures and packing figures were drawn with the program Mercury v. 2.4 [14]. The crystallographic refinement data are listed below.

L: $\mathrm{C}_{20} \mathrm{H}_{18} \mathrm{~S}_{2}, M=322.46$, colorless plate, monoclinic, space group P2(1)/c, $a=18.885(8), b$ $=5.415(2), c=7.743(3) \AA, \beta=94.422(6), U=789.4(6) \AA^{3}, Z=2, D_{c}=1.357 \mathrm{Mg} \mathrm{m}^{-3}, \mu(\mathrm{Mo}-$ $\mathrm{K} \alpha)=0.331 \mathrm{~mm}^{-1}, T=90(2) \mathrm{K}$. Total 9917 reflections, 6492 unique. Refinement of 1772 reflections (136 parameters) with $I>2 \sigma(I)$ converged at final $R_{1}=0.0328\left(R_{1}\right.$ all data $=$ $0.0349), w R_{2}=00857\left(w R_{2}\right.$ all data $\left.=0.0885\right), \mathrm{GOF}=1.066$.

$\mathbf{L}^{\mathbf{F}}: \mathrm{C}_{20} \mathrm{H}_{14} \mathrm{~F}_{4} \mathrm{~S}_{2}, M=394.43$, colorless block, monoclinic, space group P2(1)/c, $a=$ 9.4250(11), $b=5.0178(4), c=18.3077(17) \AA, \beta=92.543(3), U=864.97(15) \AA^{3}, Z=2, D_{c}=$ $1.514 \mathrm{Mg} \mathrm{m}^{-3}, \mu(\mathrm{Mo}-\mathrm{K} \alpha)=0.349 \mathrm{~mm}^{-1}, T=100(2) \mathrm{K}$. Total 6428 reflections, 1824 unique. Refinement of 1824 reflections (118 parameters) with $I>2 \sigma(I)$ converged at final $R_{1}=$ $0.0341\left(R_{1}\right.$ all data $\left.=0.0521\right), w R_{2}=0.0704\left(w R_{2}\right.$ all data $\left.=0.0779\right), \mathrm{GOF}=1.051$. 
1: $\mathrm{C}_{40} \mathrm{H}_{36} \mathrm{AgF}_{6} \mathrm{PS}_{4}, M=897.77$, colorless hexagonal block, monoclinic, space group $P 2(1) / \mathrm{c}$, $a=10.1519(6), b=19.9937(12), c=19.7056(12) \AA, \beta=102.1989(8), U=3909.4(4) \AA^{3}, Z=$ 4, $D_{c}=1.525 \mathrm{Mg} \mathrm{m}^{-3}, \mu(\mathrm{Mo}-\mathrm{K} \alpha)=0.828 \mathrm{~mm}^{-1}, T=90(2) \mathrm{K}$. Total 35930 reflections, 9345 unique. Refinement of 9345 reflections (496 parameters) with $I>2 \sigma(I)$ converged at final $R_{1}$ $=0.0191\left(R_{1}\right.$ all data $\left.=0.0214\right), w R_{2}=0.0483\left(w R_{2}\right.$ all data $\left.=0.0496\right), \mathrm{GOF}=1.041$.

2: $\mathrm{C}_{20} \mathrm{H}_{14} \mathrm{AgF}_{10} \mathrm{PS}_{2}, M=647.27$, colorless hexagonal block, monoclinic, space group $P 2(1) / \mathrm{c}$, $a=11.7350(5), b=8.1598(4), c=23.9413(10) \AA, \beta=91.1591(13), U=2292.04(18) \AA^{3}, Z=$ $4, D_{c}=1.876 \mathrm{Mg} \mathrm{m}^{-3}, \mu(\mathrm{Mo}-\mathrm{K} \alpha)=10.263 \mathrm{~mm}^{-1}, T=90(2) \mathrm{K}$. Total 11806 reflections, 4160 unique. Refinement of 4160 reflections (371 parameters) with $I>2 \sigma(I)$ converged at final $R_{1}$ $=0.0614\left(R_{1}\right.$ all data $\left.=0.0617\right), w R_{2}=0.1580\left(w R_{2}\right.$ all data $\left.=0.1583\right), \mathrm{GOF}=1.193$.

\section{Results and Discussion}

\subsection{Structural comparison of ligands $L$ and $L^{F}$}

Ligands $\mathrm{L}$ and $\mathrm{L}^{\mathrm{F}}$ are similar acyclic thioether $\left(\mathrm{S}_{2}\right)$ compounds that differ only in the $\mathrm{F}$ substituents on the central phenyl ring. While ligand $\mathrm{L}$ is a known compound, $\mathrm{L}^{\mathrm{F}}$ was synthesized by reacting the tetrafluoro-substituted precursor bis(bromomethyl)tetrafluorobenzene with thiophenol in the presence of potassium hydroxide as a white solid in $62 \%$ yield after recrystallization. Due to the presence of flexible C-S bonds in both ligands, the conformations of two ligand molecules may vary in the solid state, in particular upon coordinating to silver(I) ions. In addition, it would be interesting to ascertain whether fluoro-substitution has a significant influence on the solid state structure of the ligands and their coordination chemistry with silver(I). To initialize the research, goodquality crystals of the ligands $\mathrm{L}$ and $\mathrm{L}^{\mathrm{F}}$ were first obtained through slow evaporation of their $\mathrm{CH}_{2} \mathrm{Cl}_{2}-\mathrm{MeOH}$ solutions and both structures are determined by X-ray diffraction technique. $\mathrm{X}$-ray structural analysis reveals that although two ligands crystallize in the same monoclinic space group $\left(P 2_{1} / \mathrm{c}\right)$, their molecular conformations and packing patterns are essentially different in the solid state. Crystal structure of L is exhibited in Fig. 1. In the asymmetric unit there contains only one half of the ligand molecule, and the second half of L was generated by symmetry (operation code: $-\mathrm{x}, \mathrm{y}+1 / 2,-\mathrm{z}+1 / 2)$. The atoms $(\mathrm{C} 1, \mathrm{~S} 1, \mathrm{C} 7, \mathrm{C} 8)$ reside in an 
anti-staggered conformation and the torsional angle of C1-S1-C7-C8 is $175.04(9)^{\circ}$, with C1S1-C7 and S1-C7-C8 angles being 103.04(7) ${ }^{\circ}$ and 107.80(9) $)^{\circ}$, respectively. The dihedral angle between the side and central phenyl rings is around $68.5^{\circ}$ and the distance between the centroids of side and central phenyl rings is around $6.77 \AA$ A . Upon packing, significant intermolecular C-H... $\pi$ stacking interactions are observed for the aromatic domains (Fig. 1b). The C-H... $\pi$ contacts occur between the side phenyl rings of adjacent molecules as well as between the central phenyl rings, and the shortest $\mathrm{H} . . . \pi$ (centroid) distance is approximately $2.81 \AA$, falling in the range of common C-H... $\pi$ interactions observed in crystals [15].

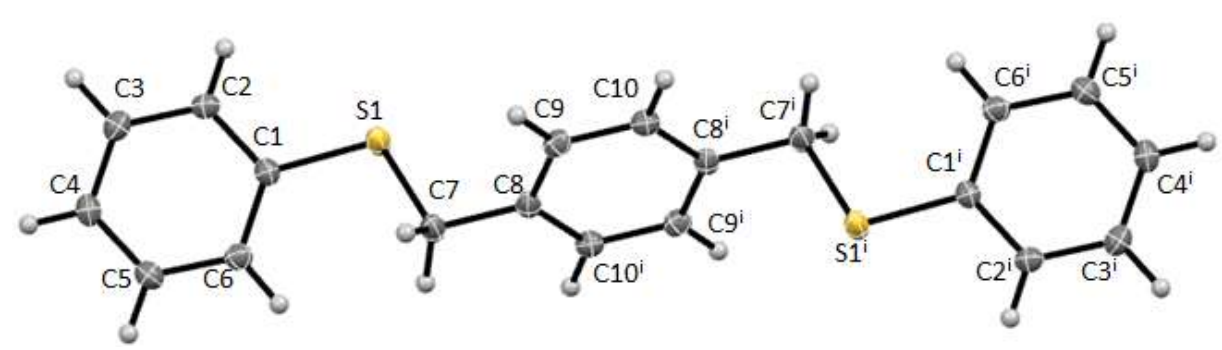

(a)

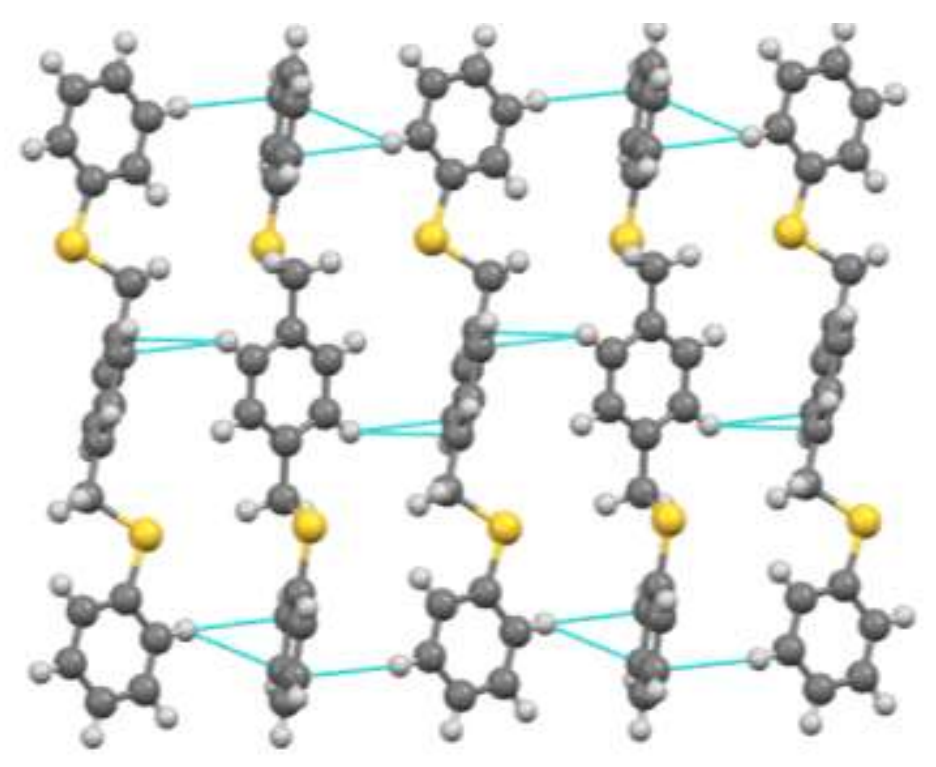

(b)

Fig. 1. (a) The ORTEP representation of the crystal structure of $\mathrm{L}$ at $50 \%$ thermal ellipsoid probability. (b) The packing mode of $\mathrm{L}$ showing intermolecular $\mathrm{C}-\mathrm{H} \ldots \pi$ interactions (cyan dashed lines). 


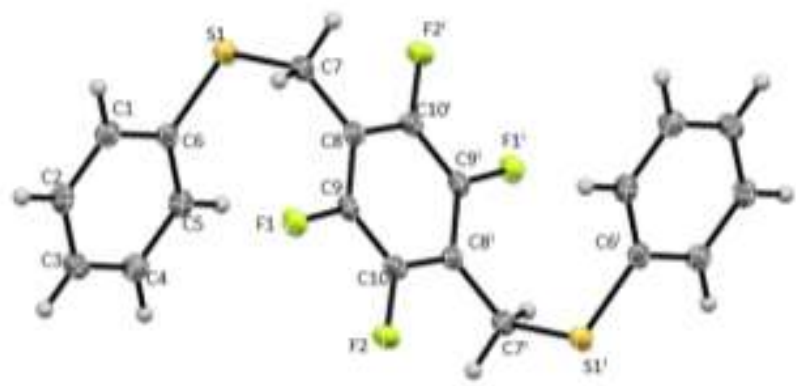

(a)

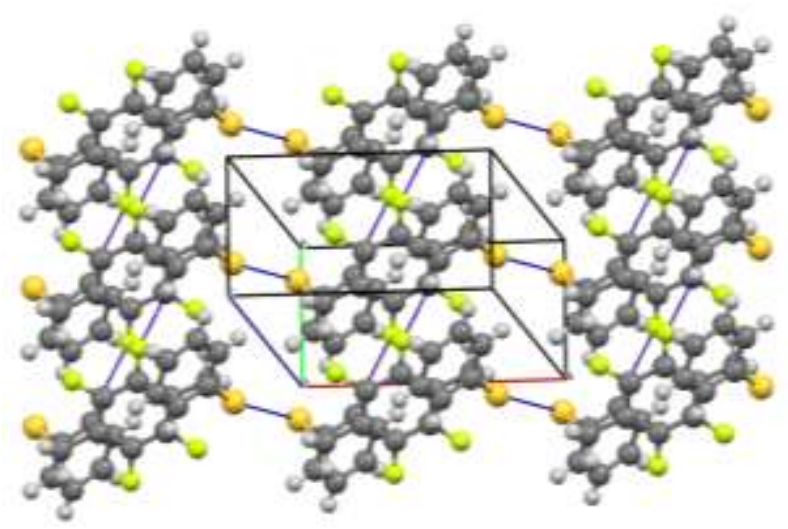

(b)

Fig. 2. (a) The ORTEP representation of the crystal structure of $\mathrm{L}^{\mathrm{F}}$ at $50 \%$ thermal ellipsoid probability. (b) The packing mode of $\mathrm{L}^{\mathrm{F}}$ showing intermolecular $\mathrm{S}$... $\mathrm{S}$ contacts (blue lines) and C-H...F hydrogen bonds (brown lines).

In contrast, the solid state structure of $\mathrm{L}^{\mathrm{F}}$ displays quite different features, although the molecule is also centrosymmetric and only one half of $\mathrm{L}^{\mathrm{F}}$ is included in the asymmetric unit of the crystal (Fig. 2a). First, the molecular conformation is largely distinct with that of L. In $\mathrm{L}^{\mathrm{F}}$, atoms $(\mathrm{C} 6, \mathrm{~S} 1, \mathrm{C} 7, \mathrm{C} 8)$ locate in a gauche-staggered conformation and the torsional angle of C6-S1-C7-C8 is $70.95(14)^{\circ}$, in sharp contrast to that in the crystal structure of L. In addition, angles C6-S1-C7 and S1-C7-C8 are 100.39(8) ${ }^{\circ}$ and 112.00(12 $)^{\circ}$, respectively. The side and central phenyl rings stay much closer to each other with the centroid distance being approximately $4.89 \AA$, compared to that in the structure of L. The dihedral angle between the side and central phenyl rings is around $64.89^{\circ}$. Second, the intermolecular packing mode of $\mathrm{L}^{\mathrm{F}}$ is also distinct. Due to the presence of fluorine atoms, intermolecular C-H...F hydrogen bonds between the side and central phenyl rings in adjacent molecules are observed, which is not unusual as such intermolecular interactions have long been known in crystals of fluorobenzene compounds [16]. The H...F distance is approximately $2.51 \AA(<\mathrm{C}-\mathrm{H}$...F $=$ 
$169.73(3)^{\circ}$ ), belonging to the values for strong C-H...F interactions [16]. In addition, the molecular packing along the $a c$ direction is governed by intermolecular S...S interactions with a S...S distance of 3.572(3) $\AA$ (shorter than twice the van der Waals radius of sulfur (3.7 $\AA)$ ), indicating significant S...S nonbonded contacts [17]. Thus, the comparison on both the molecular conformations and packing patterns between $\mathrm{L}$ and $\mathrm{L}^{\mathrm{F}}$ reveals a remarkable role fluoro-substituents played in organic crystals.

\section{2. silver(I) coordination polymers 1 and 2}

Having established that tetrafluoro-substituents on the central phenyl ring of thioether ligands are critical for the different molecular conformations as well as intermolecular interactions, we were interested to explore the coordination chemistry of ligands $\mathrm{L}$ and $\mathrm{L}^{\mathrm{F}}$ with silver(I) ions as well as the impact of fluoro-substitution on metal coordination. The reaction of $\mathrm{L}$ with two equivalents of $\mathrm{AgPF}_{6}$ in a $\mathrm{CH}_{2} \mathrm{Cl}_{2}-\mathrm{MeOH}$ solution afforded colorless crystals of 1 in good yield after slow evaporation, which are suitable for X-ray diffraction analysis. The bulk sample of $\mathbf{1}$ was characterized by $\mathrm{IR}$, elemental analysis and structurally analyzed by X-ray crystallography. Elemental analysis data reveals an empirical formula of $\operatorname{Ag}(\mathrm{L})_{2} \mathrm{PF}_{6}$, suggesting a 1:2 metal-to-ligand ratio in $\mathbf{1}$, although excess of $\mathrm{AgPF}_{6}$ was added. The existence of $\mathrm{PF}_{6}^{-}$ion in the crystals was confirmed by its IR spectrum showing strong absorption at ca. 834 and $556 \mathrm{~cm}^{-1}$, which are owing to the characteristic stretching and bending of $\mathrm{PF}_{6}^{-}$. X-ray structural analysis confirmed the formation of a polymeric network of 1 through silver(I)-sulfur coordination (Fig. 3). 1 crystallizes in the monoclinic space group $P 2_{1} / \mathrm{c}$ and in the asymmetric unit overall two ligand molecules are observed. In addition, one independent silver(I) center and $\mathrm{PF}_{6}^{-}$ion are present. All bond distances and angles are unexceptional and similar to those reported in known Ag-thiother compounds [6]. Interestingly, in 1 two different ligand conformations of $\mathrm{L}$ were observed upon coordinating to silver(I), attributed to the flexibility of thioether bonds (Fig. 3b). One of the conformations is close to that in crystals of free L, while another one is severely bent. The silver(I) center adopts a $\mathrm{S}_{4}$ coordination environment with a pseudo-tetrahedral geometry. Each silver(I) ion coordinates to four sulfur donors from four distinct ligands, while each ligand binds to two distinct silver(I) centers via its two sulfur atoms to form an extended infinite structure in three dimensions (Fig. 3c). The polymeric structure observed here is apparently different from the 
2-D grid-like net in crystals of $\mathrm{Ag}\left(\mathrm{L}^{\prime}\right)_{2}\left(\mathrm{PF}_{6}\right)\left(\mathrm{L}^{\prime}=1,3\right.$-bis(methylthiomethyl)benzene) [8], although the silver(I) ions in the latter structure feature similar pseudo-tetrahedral coordination geometry.

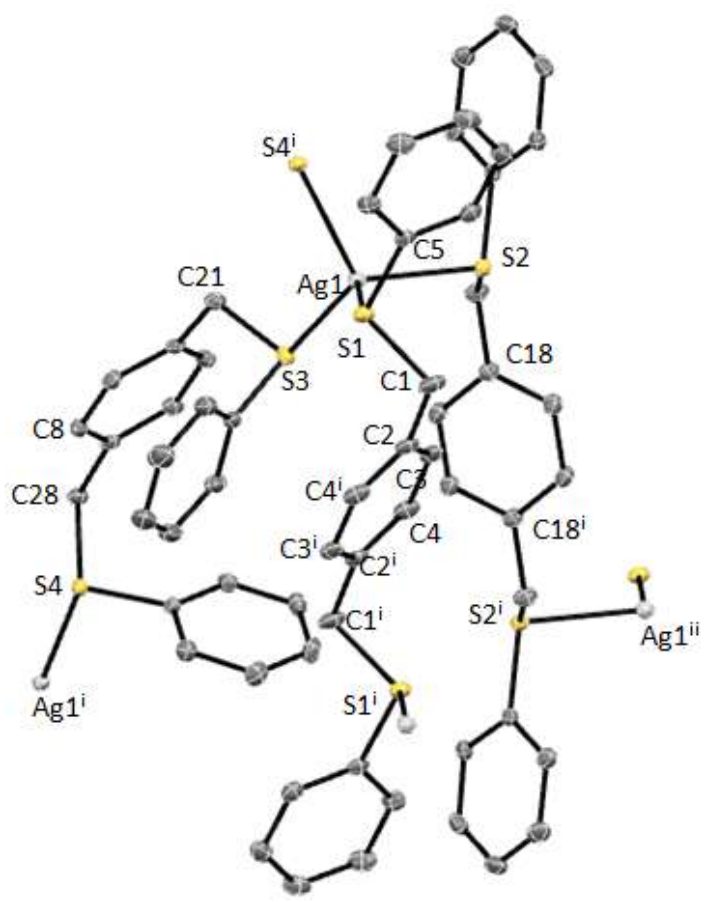

(a)

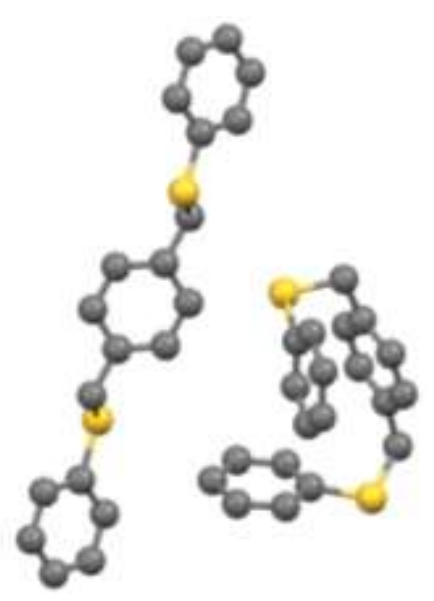

(b) 


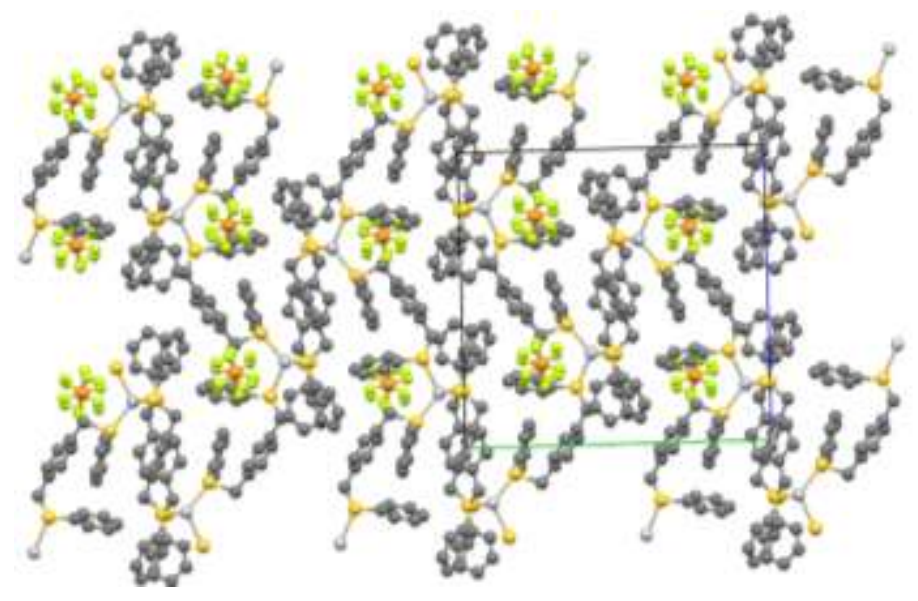

(c)

Fig. 3. (a) The ORTEP representation of the crystal structure of cationic 1 at $50 \%$ thermal ellipsoid probability $\left(\mathrm{PF}_{6}{ }^{-}\right.$ions are omitted for clarity). (b) Two types of ligand conformations existing in 1. (c) The 2-D framework sheet viewing down the crystallographic $a$ axis.

Next, we explored the reaction of $\mathrm{L}^{\mathrm{F}}$ with $\mathrm{AgPF}_{6}$ under the same conditions, in order to further study the effect of fluoro-substitution in metal coordination chemistry. Thus, goodquality crystals of $\left\{\mathrm{Ag}\left(\mathrm{L}^{\mathrm{F}}\right) \cdot \mathrm{PF}_{6}\right\}_{\mathrm{n}}(2)$ were harvested after slow evaporation of a reaction mixture of $\mathrm{L}^{\mathrm{F}}$ and $\mathrm{AgPF}_{6}$ (2.0 equiv.). Elemental analysis of the bulk sample of $\mathbf{2}$ determines a 1:1 metal-to-ligand ratio, in contrast to that in $\mathbf{1}$. The presence of $\mathrm{PF}_{6}{ }^{-}$ion in the crystals is again indicated by characteristic IR absorptions $\left(827\right.$ and $556 \mathrm{~cm}^{-1}$ ). The solid state structure was unambiguously determined by X-ray crystallography. It was revealed that $\mathbf{2}$ also crystallizes in the monoclinic space group $P 2_{1} / \mathrm{c}$. One independent ligand molecule, one $\mathrm{Ag}^{+}$ and $\mathrm{PF}_{6}{ }^{-}$are observed in the asymmetric unit (Fig. 4a). The coordination chemistry of $\mathrm{L}^{\mathrm{F}}$ with silver(I) is markedly different from that of $\mathrm{L}$. In $2, \mathrm{Ag}^{+}$is di-coordinate in an almost liner geometry ( $\left.\mathrm{S}-\mathrm{Ag}-\mathrm{S}=167.83(6)^{\circ}\right)$ with two sulfur atoms from two distinct ligands and bridges the ligand molecules to form a 1-D polymeric chain which propagates along the crystallographic $c$ axis (Fig. 4b). The Ag...Ag separation in an infinite chain is 11.971(7) $\AA$. Interestingly, the Ag-S bond lengths (2.4239(17) and 2.4281(16) $\AA$ ) in 2 are significantly shorter than those in 1 (2.5119(3)-2.6274(3) ̊). Upon packing, there are no notable intermolecular interactions observed, except the non-classical C-F... $\pi$ interactions (the shortest F...C distance is about $3.05 \AA$ ) in the fluorobenzene domains between adjacent chains (Fig. 4c). Apparently, the existence of fluoro-substituents in $\mathrm{L}^{\mathrm{F}}$ has also a critical 
influence on the silver(I) coordination chemistry under the same conditions, as seen in the crystal structures of $\mathbf{1}$ and $\mathbf{2}$.

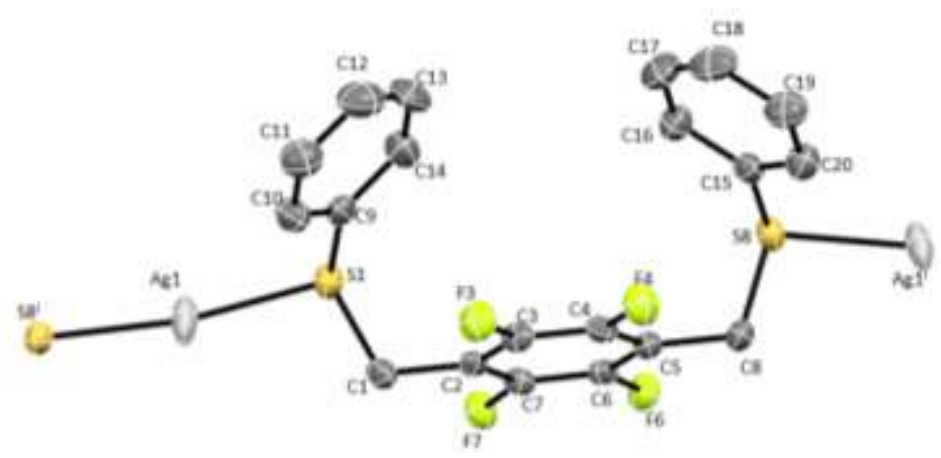

(a)

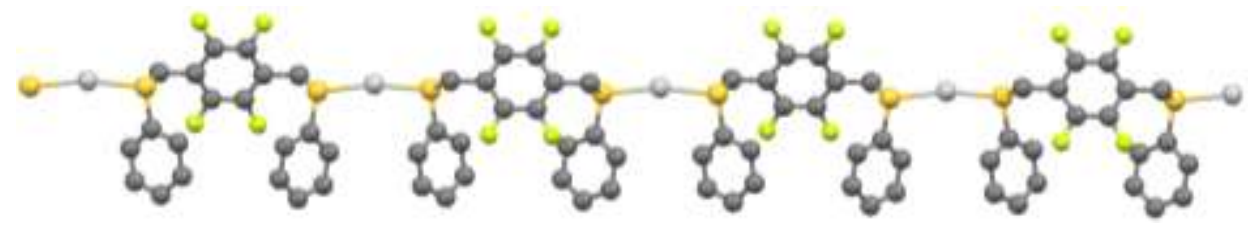

(b)

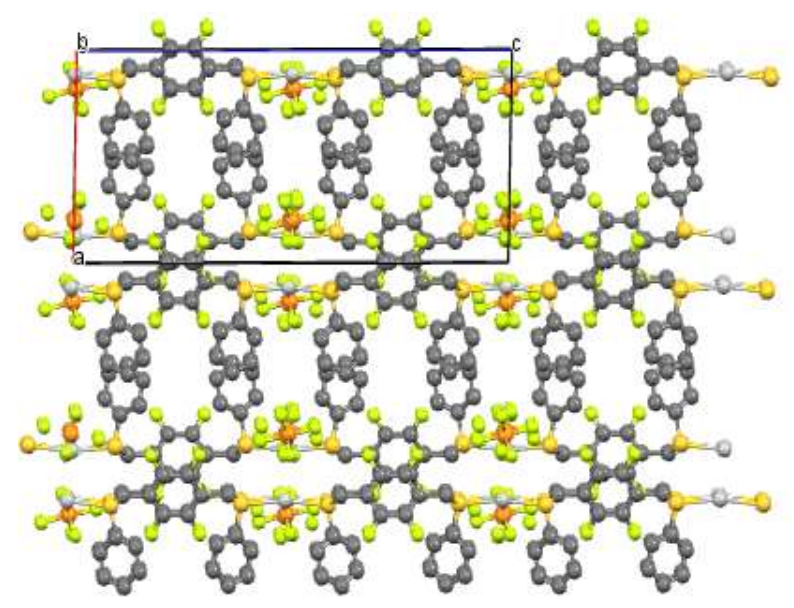

(c)

Fig. 4. (a) The ORTEP representation of the crystal structure of cationic 2 at $50 \%$ thermal ellipsoid probability $\left(\mathrm{PF}_{6}^{-}\right.$ions are omitted for clarity). (b) The 1-D polymeric chain propagating along the crystallographic $c$ axis. (c) The 3-D packing of chains viewing down the crystallographic $b$ axis.

\subsection{The Influence of fluoro-substitution}

The structural data presented here allows us to further examine the influence of fluorosubstitution on the bonding parameters in both ligands and silver(I) complexes. Relevant 
bond lengths and angles for these compounds are listed in Table 1. The data reveals that the fluoro-substitution on the central benzene ring has little impact on the corresponding bond lengths and angles in the ligand structures. For instance, the $\mathrm{C}-\mathrm{S}$ bonds in $\mathrm{L}^{\mathrm{F}}$ are about 0.02 $0.03 \AA$ longer than those in $\mathrm{L}$, whereas the $\mathrm{C}-\mathrm{C}$ bonds of central benzene rings are quite close in two compounds. Even though the bond angles are similar around S centers, the molecular conformations are remarkably different as a result of fluoro-substitution, as mentioned above. The conformational change should be attributed to the intermolecular interactions such as CH...F hydrogen bonding induced by fluorine atoms, and similar effect of fluorine substitution has been reported previously [18]. Apparently, greater influence of fluoro-substitution has been observed in the structures of the silver(I) coordination complexes. Except for the differing $\mathrm{Ag}^{\mathrm{I}}$ coordination modes and hence network structures found in $\mathbf{1}$ and $\mathbf{2}$, bond parameters are essentially different. As discussed above, the Ag-S bond lengths for 1 are in the range of 2.51-2.63 $\AA$, whereas these are around 2.42-2.43 $\AA$ for 2 containing fluorosubstituents, which is reasonable as the inductive effect of fluorine atoms would increase the electronegativity of sulfur atoms and thus strengthen the Ag-S coordination bonds. In contrast, the influence of fluorine atoms on the $\mathrm{C}-\mathrm{S}$ and $\mathrm{C}-\mathrm{C}$ bond distances is trivial for the complexes.

Table 1. Selected bond lengths $(\AA)$ and angles $\left(^{\circ}\right)$ for compounds $L, L^{F}, 1$ and 2.

\begin{tabular}{|c|c|c|c|}
\hline \multicolumn{4}{|c|}{$\mathrm{L}$} \\
\hline $\mathrm{C} 1-\mathrm{S} 1$ & $1.7597(14)$ & C7-S1 & $1.8087(14)$ \\
\hline C7-C8 & $1.5009(18)$ & C8-C9 & $1.3878(19)$ \\
\hline C9-C10 & $1.3810(18)$ & & \\
\hline $\mathrm{C} 1-\mathrm{S} 1-\mathrm{C} 7$ & $103.04(7)$ & $\mathrm{S} 1-\mathrm{C} 7-\mathrm{C} 8$ & $107.80(9)$ \\
\hline \multicolumn{4}{|c|}{$\mathrm{L}^{\mathrm{F}}$} \\
\hline C6-S1 & $1.7839(18)$ & C7-S1 & $1.8295(18)$ \\
\hline C7-C8 & $1.498(3)$ & $\mathrm{C} 8-\mathrm{C} 9$ & $1.385(3)$ \\
\hline C9-C10 & $1.376(3)$ & & \\
\hline C6-S1-C7 & $100.39(8)$ & $\mathrm{S} 1-\mathrm{C} 7-\mathrm{C} 8$ & $112.00(12)$ \\
\hline \multicolumn{4}{|l|}{1} \\
\hline $\mathrm{Ag} 1-\mathrm{S} 1$ & $2.6188(3)$ & Ag1-S2 & $2.6274(3)$ \\
\hline $\mathrm{Ag} 1-\mathrm{S} 3$ & $2.5119(3)$ & $\mathrm{Ag} 1-\mathrm{S} 4^{\mathrm{a}}$ & $2.6053(3)$ \\
\hline $\mathrm{S} 1-\mathrm{C} 1$ & $1.7921(17)$ & $\mathrm{S} 1-\mathrm{C} 5$ & $1.8202(14)$ \\
\hline $\mathrm{S} 2-\mathrm{C} 11$ & $1.8052(16)$ & $\mathrm{S} 2-\mathrm{C} 17$ & $1.8223(14)$ \\
\hline $\mathrm{S} 3-\mathrm{C} 21$ & $1.8457(13)$ & S3-C29 & $1.7822(14)$ \\
\hline $\mathrm{S} 4^{\mathrm{a}}-\mathrm{C} 28$ & $1.8267(13)$ & S4-C35 & $1.7767(13)$ \\
\hline $\mathrm{C} 1-\mathrm{C} 2$ & $1.5030(18)$ & C17-C18 & $1.5094(17)$ \\
\hline
\end{tabular}




\begin{tabular}{llll}
$\mathrm{C} 21-\mathrm{C} 22$ & $1.5017(17)$ & $\mathrm{C} 28-\mathrm{C} 25$ & $1.832(4)$ \\
$\mathrm{S} 3-\mathrm{Ag} 1-\mathrm{S} 4$ & $118.153(11)$ & $\mathrm{S} 3-\mathrm{Ag} 1-\mathrm{S} 1$ & $120.195(11)$ \\
$\mathrm{S} 4-\mathrm{Ag} 1-\mathrm{S} 1$ & $82.901(10)$ & $\mathrm{S} 3-\mathrm{Ag} 1-\mathrm{S} 2$ & $103.882(11)$ \\
$\mathrm{S} 4-\mathrm{Ag} 1-\mathrm{S} 2$ & $117.661(10)$ & $\mathrm{S} 1-\mathrm{Ag} 1-\mathrm{S} 2$ & $114.035(11)$ \\
\hline \multicolumn{1}{c}{$\mathbf{2}$} & & & \\
\hline $\mathrm{Ag} 1-\mathrm{S} 1$ & $2.4239(17)$ & $\mathrm{Ag} 1-\mathrm{S} 8^{\mathrm{g}}$ & $2.4280(16)$ \\
$\mathrm{S} 1-\mathrm{C} 1$ & $1.833(7)$ & $\mathrm{S} 1-\mathrm{C} 9$ & $1.778(7)$ \\
$\mathrm{S} 8-\mathrm{C} 8$ & $1.833(6)$ & $\mathrm{S} 8-\mathrm{C} 15$ & $1.776(7)$ \\
$\mathrm{C} 1-\mathrm{C} 2$ & $1.495(8)$ & $\mathrm{C} 8-\mathrm{C} 5$ & $1.501(8)$ \\
S1-Ag1-S8 & $167.83(6)$ & &
\end{tabular}

\subsection{Thermal Properties}

To study the thermal stability of both the ligands $\left(\mathrm{L}\right.$ and $\mathrm{L}^{\mathrm{F}}$ ) and their silver(I) complexes (1 and 2), we performed the thermogravimetric analysis (TGA) with the crystalline samples under $\mathrm{N}_{2}$ atmosphere. The corresponding TG curves for four compounds are presented in Fig. 5. As seen in Fig. 5, Ligand L is stable up to $190{ }^{\circ} \mathrm{C}$ and then experiences almost complete decomposition while being heated to $350{ }^{\circ} \mathrm{C}$. In contrast, $\mathrm{L}^{\mathrm{F}}$ is slightly less stable and decomposed completely in the temperature range of $165-295^{\circ} \mathrm{C}$. Silver(I) coordination network $\mathbf{1}$ is, however, less stable than the free ligand, and undergoes stepwise weight loss of ca. $35.2 \%$ (calc. $35.9 \%$ ) between $180^{\circ} \mathrm{C}$ and $248^{\circ} \mathrm{C}$ for the removal of one ligand molecule per structural unit, and later the loss of another ligand molecule upon further heating to around $800^{\circ} \mathrm{C}$. Silver(I) complex 2 is relatively more stable. The main coordination structure is stable up to $245^{\circ} \mathrm{C}$, after which temperature a major weight loss of $60.7 \%$ occurs upon heating to $364^{\circ} \mathrm{C}$, owing to the removal of all ligand molecules from the polymeric structure (calc. $61.0 \%$ weight loss). The results further indicate the influence of fluoro-substitution on the thermal behaviours of both ligands and their silver(I) complexes. 


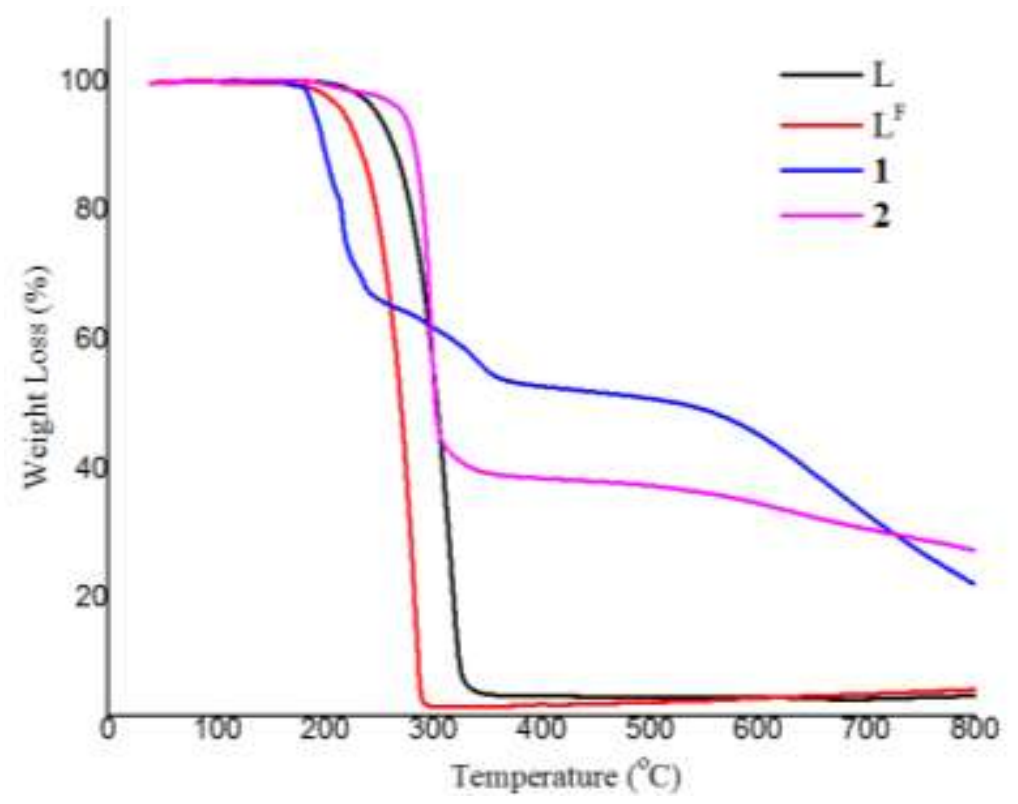

Fig. 5. The TG curves for both free ligands and silver(I) coordination polymers.

\section{Conclusions}

In summary, we have synthesized two thioether ligands, including a new fluoro-substituted thioether compound. The solid-state structures were studied for both organic crystals. It was observed that fluoro-substitution greatly affected the molecular conformations and hence their crystal packing patterns. Furthermore, the fluoro-substitution effect has been also confirmed in their $\operatorname{Ag}(\mathrm{I})$ complexes resulting from the self-assembly between ligands and $\mathrm{AgPF}_{6}$ in solution. The incorporation of fluorine atoms in the thioether ligand varied the structures of their silver(I) complexes from complex 3-D network to 1-D polymeric chain. The different thermal behaviors of both ligands and their silver(I) coordination polymers have been revealed by TG analysis. 


\section{Acknowledgements}

We are grateful to a PSC-CUNY award (\#69069-0047), a "Seed Grant" from the Office for Advanced Research and the Program for Research Initiatives for Science Majors (PRISM) at John Jay College. The National Science Foundation (Grant 0840444) is acknowledged for the Dual source X-ray diffractometer. The Natural Science Foundation of Hubei Province in China (2015CFA130 and 2013CFA015) is also acknowledged for partial support.

\section{References}

[1] (a) J.-M. Lehn, Supramolecular Chemistry: Concepts and Perspectives; VCH: Weinheim, Germany, 1995;

(b) F. Novio, J. Simmchen, N. V. Mera, L. A. Ferré, D. R. Molina, Coord. Chem. Rev., 257 (2013) 2839;

(c) J.H. Jung, J.H. Lee, J.R. Silverman, G. John, Chem. Soc. Rev., 42 (2013) 924;

(d) W.L. Leong, J.J. Vittal, Chem. Rev., 111 (2011) 688;

(e) G. Givaja, P.A. Ochoa, C.J.G. García, F. Zamora, Chem. Soc. Rev., 41 (2012) 115;

(f) Y.-Z. Zheng, Z. Zheng, X.-M. Chen, Coord. Chem. Rev. 258-259 (2014) 1;

(g) T. R. Cook, P. J. Stang, Chem. Rev. 115 (2015) 7001;

(h) J. A. Denny, Y. D. Marcetta, Chem. Rev. 115 (2015) 5248.

[2] (a) X. Zhang, W. Wang, Z. Hu, G. Wang, K. Uvdal, Coord. Chem. Rev. 284 (2015) 206;

(b) C. He, D. Liu, W. Lin. Chem. Rev. 115 (2015) 11079;

(c) C. Pettinari, A. Tăbăcaru, S. Galli. Coord. Chem. Rev. 307 (2016) 1;

(d) Y. Hasegawa, T. Nakanishi. RSC Advances 5.1 (2015) 338;

(e) G. Zhang, C. Ta, S.-Y. Cheng, J.A. Golen, A.L. Rheingold, Inorg. Chem. Commun. 48 (2014) 127;

(f) G. Zhang, G. Proni, S. Zhao, E.C. Constable, C.E. Housecroft, J.A. Zampese, M. Neuburger, Dalton. Trans. 43 (2014) 12313;

(g) E. Liu, Y.Z. Zhang, J.-W. Tan, C. Yang, L. Li, J.A. Golen, A.L. Rheingold, G. Zhang, Polyhedron 102 (2015) 41.

[3] (a) M. Li, D. Li, O’Keeffe, O.M. Yaghi, Chem. Rev. 114 (2014) 1343;

(b) U.S. Schubert, A. Winter, G.R. Newkome, Terpyridine-Based Materials, Wiley-VCH, 
Weinheim, Germany 2011, Ch. 4;

(c) E.C. Constable, Chem. Soc. Rev. 36 (2007) 246;

(d) C. E. Housecroft, Dalton Trans. 43 (2014) 6594;

(e) G. Zhang, Y. Jia, W. Chen, W.-F. Lo, N. Brathwaite, J.A. Golen, A.L. Rheingold, RSC Adv. 5 (2015) 15870;

(f) Z. Yin, G. Zhang, T. Phoenix, S. Zheng, J.C. Fettinger, RSC Adv. 5 (2015) 36156.

[4] (a) A.J. Blake, N.R. Champness, S.M. Howdle, P.B. Webb, Inorg. Chem. 39 (2000) 1035;

(b) A.J. Blake, N.R. Champness, W. Levason, G. Reid, Inorg. Chem. 35 (1996) 4432;

(c) A.J. Blake, N.R. Champness, W. Levason, G. Reid, Chem. Commun. (1995) 1277;

(d) A.J. Blake, N.R. Champness, S.M. Howdle, K.S. Morley, P.B. Webb, C. Wilson, CrystEngComm 4 (2002) 88.

[5] (a) S. Liao, C.-Y. Su, H.-X. Zhang, J.-L. Lin, Z.-Y. Zhou, H.-Q. Liu, A.S.C. Chan, B.-S. Kang, Inorg. Chim. Acta 336 (2002) 151;

(b) L. Han, B. Wu, Y. Xu, M. Wu, Y. Gong, B. Lou, B. Chen, M. Hong, Inorg. Chim. Acta 358 (2005) 2005;

(c) R.M. Silva, M.D. Smith, J.R. Gardinier, Inorg. Chem. 45 (2002) 2132;

(d) H.-Z. Dong, H.-B. Zhu, X. Liu, S.-H. Gou, Polyhedron 27 (2008) 2167;

(e) A. Mizar, C. Pettinari, F. Marchetti, I. Timokhin, A. Crispini, Inorg. Chem. Commun. 24 (2012) 20;

(f) R.K. Mudsainiyan, A.K. Jassal, M. Arora, S.K. Chawla, J. Chem. Sci. 127 (2015) 849.

[6] (a) D. Liao, J. Chen, H. Zhou, Y. Wang, Y. Li, C. Yu, Anal. Chem. 85 (2013) 2667;

(b) M.-L. Ho, C.-H. Shih, C.-H. Lee, G.-H. Lee, CrystEngComm, 13 (2011) 992;

(c) K.K. Bisht, A.C. Kathalikkattil, E. Suresh, RSC Adv. 2 (2012) 8421;

(d) M. Osawa, I. Kawata, R. Ishii, S. Igawa, M. Hashimotoab, M. Hoshino, J. Mater. Chem. C, 1 (2013) 4375;

(e) A. Spangenberg, J.-P. Malval, H.A. Kilig, J.-L. Fillaut, F. Stehlin, N. Hobeika, F.M. Savary, O. Soppera, Macromolecules 45 (2012) 1262.

[7] (a) K. Li, Z. Xu, H. Xu, P.J. Carroll, J.C. Fettinger, Inorg. Chem. 45 (2006) 1032;

(b) X. Gan, M. Munakata, T. Kuroda-Sowa, M. Maekawa, Bull. Chem. Soc. Jpn. 67 (1994) 3009;

(c) G. Huang, H. Xu, X.-P. Zhou, Z. Xu, K. Li, M. Zeller, A.D. Hunter, Cryst. Growth Des.7 (2007) 2542;

(d) M.B. Inoue, M. Inoue, M.A. Bruck, Q. Fernando, Chem. Commun. (1992) 515;

(e) J.C. Zhong, Y. Misaki, M. Munakata, T. Kuroda-Sowa, M. Maekawa, Y. Suenaga, H. 
Konaka, Inorg. Chem. 40 (2001) 7096.

[8] H. Xiong, L. Li, E Liu, C. Yang, Y. Z. Zhang, J. C. Fettinger, G. Zhang, Polyhedron, 2016, in press.

[9] (a) J.-P. Begue, D. Bonnet-Delpon, J. Fluorine Chem. 127 (2006) 992;

(b) C. Isanbor, D. O’Hagan, J. Fluorine Chem. 127 (2006) 303;

(c) I. Ojima, Fluorine in Medicinal Chemistry and Chemical Biology; Wiley-Blackwell:

Chichester, (2009);

(d) I. Ojima, J. Org. Chem. 78 (2013) 6358;

(e) J. Wang, M. Sánchez-Roselló, J.L. Aceña, C. del Pozo, A. E. Sorochinsky, S. Fustero, V. A. Soloshonok, H. Liu, 114 (2014) 2232;

(f) E.P. Gillis, K.J. Eastman, M.D. Hill, D.J. Donnelly, N.A. Meanwell, J. med. chem., 58 (2015) 8315.

[10] A. C. Stuart, J.R. Tumbleston, H. Zhou, W. Li, S. Liu, H. Ade, W. You, J. Am. Chem. Soc. 135 (2013) 1806.

[11] C. Ni, J. Hu. Chem. Soc. Rev. 45 (2016) 5441.

[12] W. Chen, J.R. Widawsky, H. Vázquez, S.T. Schneebeli, M.S. Hybertsen, R. Breslow, L. Venkataraman, J. Am. Chem. Soc. 133 (2011) 17160.

[13] Z. A. Page, Y. Liu, E. Puodziukynaite, T. P. Russell, T. Emrick, Macromolecules 49 (2016) 2526.

[14] Mercury: Visualization and analysis of crystal structures. C.F. Macrae, P.R. Edgington, P. McCabe, E. Pidcock, G.P. Shields, R. Taylor, M. Towler, J. van de Streek, J. Appl. Crystallogr. 39 (2006) 453.

[15] M. Nishio, CrystEngComm 6 (2004) 130-158.

[16] V.R. Thalladi, H.-C. Weiss, D. Bläser, R. Boese, A. Nangia, G.R. Desiraju, J. Am. Chem. Soc. 120 (1998) 8702.

[17] T. N. Guru Row, R. ParthaSarathy, J. Am. Chem. Soc. 103 (1981) 477.

[18] (a) A. Schwarzer, E. Weber, Cryst. Growth Des. 8 (2008) 2862.

(b) I. Alkorta, I. Rozas, J. Elguero, J. Fluo. Chem. 101 (2000) 233. 
Graphic Abstract - Pictogram

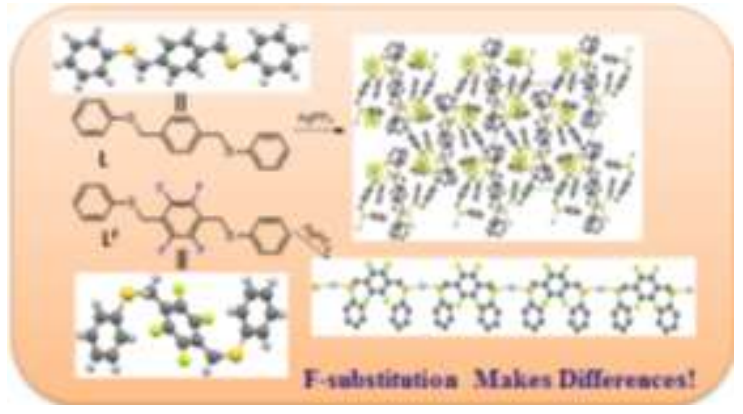

